\title{
Therapeutic area influences drug development costs
}

CNS and anti-infective treatments are the most expensive to develop.
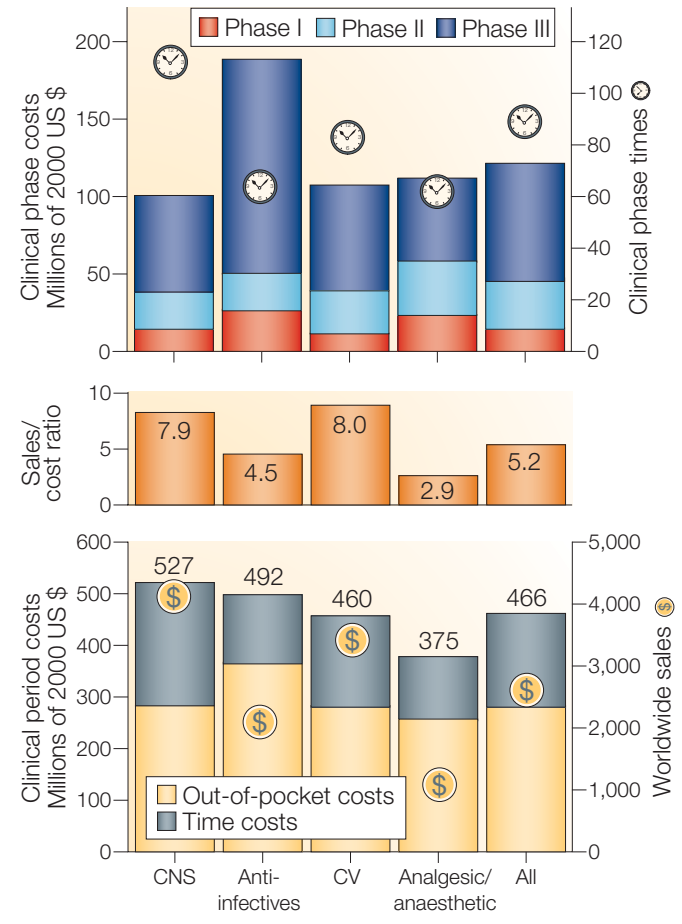

Simon Frantz

The cost and time involved in drug development is highly dependent on therapeutic class, according to a new report from the Tufts Center for the Study of Drug Development.

Drugs targeting the central nervous system (CNS) are the most expensive to develop. Compared with an overall average of US $\$ 466$ million, total out-of-pocket and time costs for the clinical and approval phases were \$527 million (year 2000\$). Anti-infectives were also above average with a cost of $\$ 492$ million. Cardiovascular and analgesic/anaesthetics were below average, with costs of $\$ 460$ million and $\$ 375$ million, respectively (see figure; data from Tufts Center for the Study of Drug Development).

"The costs differ at component levels, and analyses across these areas highlight how to contain development costs and bring new drugs to market more quickly," says Joseph DiMasi, Director of Economic Analysis at the Tufts Center for the Study of Drug Development, and lead author of the study.
The Tufts study, released in summary form in the Center's Impact Report and due to be published in full in the August issue of Drug Information Journal, further analyses the data on which the widely quoted $\$ 802$ million average cost of drug development is based. With preclinical data difficult to assign precisely to therapeutic area, the new study focused on the clinical and approval costs and times of 69 investigational drugs that first entered clinical testing worldwide between 1983 and 1994.

Clinical development times were highest for CNS and cardiovascular treatments, but clinical costs were lowest (see figure). The reverse was true for anti-infectives and analgesics/anaesthetics.

Comparison with a similar Tufts analysis of drugs that entered clinical trials between 1970 and 1982 (DiMasi, J. A. et al. Pharmacoeconomics 7, 152-169 (1995)) reveals how development costs evolved over a decade. The most striking change was in the cost of anti-infectives, which has risen from $25 \%$ below average to $6 \%$ above average. "This increase in costs has been driven

\section{Stand by your brand}

The industry is adopting creative seduction techniques to persuade customers to buy its products.

\section{Sophie Petit-Zeman, London}

Loyalty schemes that have proved successful for products such as airline tickets and dog food are now being adopted by pharmaceutical companies to retain market share.

In April, Pfizer launched its 'Viagra Value Card' programme in the United States, offering a free seventh prescription to men who buy six. With vardenafil (Levitra; Bayer/GlaxoSmithKline) and tadalafil (Cialis; Lilly) providing the first competition to sildenafil since its launch six years ago, the Viagra loyalty programme could help reverse a trend which has seen market share of new prescriptions fall from almost $80 \%$ to $65 \%$.

But Daniel Watts, a spokesman for Pfizer, denies that the programme is a response to competitors, saying, "We're always looking for ways to communicate our messages and this way demonstrates leadership and rewards loyalty."

Such loyalty schemes are seen as a way to drive repeat business and lock customers into a brand, who will then recommend business to their colleagues and friends by word of mouth, a process known as viral marketing. For example,
Air Miles was launched in the United Kingdom in 1988 as a means of helping British Airways dispose of unsold seats. Now, 100 partner companies issue Air Miles to more than six million collectors.

Wally Olins, international corporate identity guru and author of On Brand, in which he argues that successful companies share 'seduction' ability — otherwise known as marketing says of Pfizer's loyalty scheme, "It's a very good and obvious idea. It's been done with dog food for years - buy six dollops get one free, why not Viagra?"

Is it a response to market forces? Olins says it might well be, adding, "It's marketing spiel to say otherwise." He says that reducing price could be the next step, a view elaborated by international marketing strategist Matthew Driver. "Such initiatives are clearly focused on market entrants. Sales promotions that drive volume put pressure on competitors as manufacturers can bump up production and reap the benefits of economies of scale, which could in turn be passed on as reduced price to consumers."

Loyalty schemes have been slow to reach the drug market because of ethical concerns. But

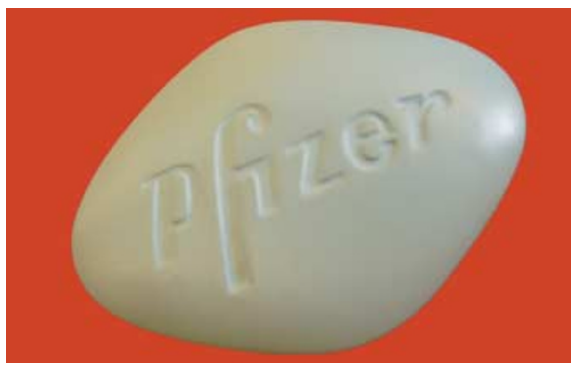

Companies such as Pfizer are introducing customer loyalty schemes for their big sellers.

Driver says, "There would be 'no go' areas such as drugs that were additive or potentially hazardous with extended use, but for reliable drugs with lifestyle impacts such approaches are good business practice."

An alternative incentive scheme recently launched by Novartis for antihypertensives has attracted US government backing. Through 'Take Action for Healthy Blood Pressure', Novartis offers a free 30-day trial of valsartan (Diovan), valsartan/hydrochlorothiazide (Diovan HCL) or amlodipine/benazepril hydrochloride (Lotrel), with a money-back guarantee for up to four months costs if, at the highest recommended dose, patients do not achieve their target blood pressure. They also get a free monitor and no-strings-attached hypertension information. 
largely, but not exclusively, by HIV treatments, which weren't being developed in the previous analysis," says DiMasi.

Cardiovascular drug costs remained around the average value, and CNS drugs remained stable, rising slightly from $10 \%$ to $13 \%$ above average. Analgesics/anaesthetics cannot be compared as the first study looked at NSAIDs only.

The difference in returns from each therapeutic area hints at how companies are forming strategy decisions. The ratio of life-cycle worldwide sales for new drugs approved during 1990-1994 to the development costs calculated in the study was greatest for CNS and cardiovascular drugs (see figure), which included big-sellers such as SSRIs and ACE inhibitors. Anti-infectives and analgesics/ anaesthetics fared less well. This difference in profitability could explain companies' decisions on allocation of R\&D resources, says Ken Kaitin, Director of the Tufts Center. "Our findings are consistent with a model that suggests $\mathrm{R} \& \mathrm{D}$ efforts have generally shifted towards high net return, and away from low-return therapeutic areas."

The American Nurses Association and Society of Hypertension broadly back the scheme. Barbara Alving, acting Director of the National Heart, Lung and Blood Institute said: "If this really gets the attention of those who otherwise would not have tried to have their blood pressure under control, then it's worthwhile. We have to look at it and say 'what is the greater good to be obtained here?"”

However, Jerry Avorn of Harvard University's Brigham and Women's Hospital says this is "a goofy idea [which] pushes therapy in a direction that is counter to what a lot of current research suggests is appropriate." Critics such as Avorn say that $\$ 1.2$ billion would be saved in the US if doctors followed current guidelines for prescribing cheaper antihypertensives such as diuretics.

But product guarantees reassure customers about efficacy, says Driver, and they seem to work. One example reported in the news illustrates how this could be true. A 61-year-old man with diabetes was previously reluctant to control his blood pressure of $155 / 75$, but was apparently persuaded by the guarantee, saying, "They must be pretty sure of their product."

\section{NEWS IN BRIEF}

\section{FDA rejects OTC status for contraceptive}

The FDA has rejected the over-the-counter sale of the emergency contraceptive levonorgestrel (Plan B; Barr), despite the positive decision given by the advisory committee. The committee voted 22 to 5 that the non-prescription-setting programme was adequate with respect to consumer access and safe use. However, the FDA said that Barr had not shown that adolescent women could understand the product instructions without the intervention of a physician, the first time that the FDA has requested this information for an OTC product. The agency has vigorously defended accusations that the decision was politically motivated.

\section{Off-label use of gabapentin reprimanded}

Pfizer has pleaded guilty to illegally promoting off-label uses of gabapentin (Neurontin). The drug, developed by Warner Lambert, is approved for partial seizures and post-herpetic neuralgia, but is promoted for at least 11 off-label uses, including restless leg syndrome, bipolar disorder and migraines. David Franklin, a medical liaison expert for Warner Lambert, successfully charged Pfizer with using fraudulent scientific evidence, such as suppressing study results and using ghostwriters, to promote the off-label use of the drug. Pfizer agreed to pay a total of US $\$ 430$ million in fines and damages - the second largest given in the industry.

\section{Approval for new antithrombotic}

AstraZeneca's keenly awaited thrombosis drug ximelagatran (Exanta) has received the first round of approvals in the European Union. Ximelagatran, the first alternative to warfarin for 60 years, was approved for the prevention of thrombosis in patients undergoing hip and knee surgery. The United Kingdom and Ireland have not approved the treatment, as they want to discuss the timing of its use. But AstraZeneca says the countries have not questioned the safety or efficacy of the treatment.

\section{First statin to be sold over the counter}

The United Kingdom government announced that Merck will get the go-ahead to market a 10-mg dose of simvastatin, known as Zocor Heart Pro, over the counter in UK pharmacies. Statins are prescribed to 1.8 million UK patients at a cost of more than $£ 700$ million (US $\$ 1.25$ billion) to the National Health Service. The government is hoping to make simvastatin available for primary prevention of heart disease to a broader population without costing the government any extra money. In the highly competitive statin market, Merck hopes that the move will help rejuvenate sales of its off-patent product. The UK is the first country to sell an OTC statin, and it will be available in July for reducting the risk of a first major coronary event in people likely to be at moderate risk of coronary heart disease.

\section{Pfizer shifts R\&D strategy}

Pfizer's CEO Hank McKinnell said the company is moving from short to longer term R\&D by seeking biotech acquisitions to fill its pipeline. Several of Pfizer's most important drugs are expected to lose patent protection in the next few years, and the move from in-licensing to improving core R\&D capabilities seems to be due to the current favourable climate for making value-for-money acquisitions. Pfizer hinted at its intentions last year when it acquired the US biotechnology company Esperion for US $\$ 1.3$ billion.

\section{NIH addresses staff conflicts of interest}

A National Institutes of Health $(\mathrm{NIH})$ panel has proposed changes to its employment rules to address criticism about conflicts of interest among its senior staff. The changes were proposed after an article in the Los Angeles Times in December 2003 suggested shortcomings in the agency's existing conflict-of-interest policies. The panel said the $\mathrm{NIH}$ should bar its most senior officials from earning money by consulting for industry or academic institutions. It recommended that scientists who are allowed to do consultancy work should limit their compensation to $50 \%$ of their government salaries and spend no more than 400 hours a year on the work. Nobody at the NIH should be allowed to accept stocks or stock options as payment, but the health secretary should raise the cap on the salaries as a recruitment incentive.

\section{Antisense cancer drug shows no effect on survival}

The antisense treatment for BCL2, oblimersen (Genasense; Genta/Aventis), seems not to have an effect on progression-free survival, according to an FDA Advisory Committee. The committee voted 11 to 5 that oblimersen plus dacarbazine showed a difference in response rate from dacarbazine alone in patients with metastatic melanoma. However, the committee voted 12 to 4 that the Genta pivotal trial did not conclusively show a "real effect” on progression-free survival. Genta has withdrawn this application for approval and reduced its workforce by nearly a half. The company has stopped marketing gallium nitrate (Ganite) for hypercalcaemia, which was intended to help establish its sales force before the launch of oblimersen. This now allows for the company to devote its remaining money - an estimated US $\$ 67$ million - to resubmitting approval data for oblimersen. 